\title{
CUTTING TESTS WITH CEMENTED TUNGSTEN CARBIDE LATHE TOOLS
}

\author{
By T. G. Digges
}

ABSTRACT

This investigation was made for the purpose of developing a method of testing cemented tungsten carbide lathe tools under heavy duty and to extend to the new cutting material some of the laws originally developed by Taylor and his associates for cutting with carbon and high-speed steel tools. Relations were determined between the speed, feed, depth of cut, and tool life for a selected form and size of tool. All tests were made dry in cutting 3.5 per cent nickel-steel forgings, heat treated to give tensile strengths within the range of 85,000 to 110,000 lbs./in. ${ }^{2}$ The results are presented in both graphic and tabular forms.

\section{CONTENTS}

I. Introduction

II. Previous investigations

III. Methods of tests

1. Equipment.... 366

2. Procedure

3. Tool failure

IV. Effect of cutting speed on tool life 370

V. Effect of feed and depth on the cutting speed 373

VI. General comments on lathe tests _._. 379

VII. Summary and conclusions._. 382

VIII. Acknowledgments

\section{INTRODUCTION}

Cemented tungsten-carbide tools were first placed on the market on a commercial basis in Europe in 1926 and in the United States several years later. The rapid development of this material during the past year has made possible its extensive use for tools throughout this country and abroad. The records of production with these tools have already shown that this new cutting material will occupy a most important place in our industrial life.

The experiments described in this report relate primarily to a studr of lathe-tool performance as affected by the conditions of cutting, such as variations in spceds, feeds, and depths, while the composition, the size, and form of the tools and cutting materials were not raried. The investigation was for the purpose of developing a method of testing tungsten-carbide tools under heavy duty and to establish some of the laws of cutting which define the approximate relations between tests of short duration, which might be made in the laboratory, and long-time cutting required in practical service. 'The need of such information is shown by the large number of inquiries received by the National Bureau of Standards from consumers. 


\section{PREVIOUS INVESTIGATIONS}

No attempt will be made to review the abundant literature published since the introduction of tungsten carbide as a cutting material. The articles published have dealt primarily with outstanding production records and other phases not directly related to the field to be covered. Such data may be used to advantage, and important technical publications containing information on the subject under discussion will be referred to in the individual sections of this report.

\section{METHODS OF TESTS}

\section{EQUIPMENT}

A 36-inch heavy-duty engine lathe, driven by a 40 h. p. 220 volt d. c. shunt motor, was selected. (See fig. 1.) A "link belt" chain was used to insure a positive drive. Accurate speed control of the work piece was secured by using the several gearing ratios of the lathe and by changing the speed of the motor with a variable resistance in the field circuit. Experiments showed that it was necessary to increase the rate of speed of the motor in order to prevent excessive slowing down or stalling under heavy loads.

A special tool holder was designed to give ample support to the test tool near the cutting edge. This was firmly clamped in the 4-bolt tool post holder shown in Figure 1.

A "live center" (tailstock) containing a ball bearing and having the form and dimensions shown in Figure 2 was used instead of the customary "dead center." Its insertion required considerable time and labor, but it avoided lubrication troubles common with the "dead center."

A single pointed cutting tool was selected and its form was similar to that commonly employed for heavy-duty roughing work. Its form and dimensions, as shown in Figure 3, consisted of tungstencarbide tips approximately 0.18 inch thick, 0.31 inch wide, and 0.87 inch long, copper brazed on a shank 0.5 inch wide, 1 inch thick, and 7 inches long. The tools had a plane angle of $90^{\circ}$ and were ground to $6^{\circ}$ front and side clearance, $0^{\circ}$ back slope, $14^{\circ}$ side slope, $10^{\circ}$ back side relief, and the radius of the nose was 0.0625 inch. The edge of the tool from this are along its cutting edge was ground to a contour of 1.75 -inch radius for 0.4375 inch. All tools were hollow ground to a depth of 0.003 to 0.006 inch at approximately 0.25 inch from the cutting edge of the tools. Special grinding wheels of silicon carbide were used for grinding the tools.

The tools used in this investigation were manufactured by the Carboloy Co. (Inc.) by certain sintering operations in which the fine particles of tungsten carbide were cemented firmly together with cobalt, and the material is referred to as cemented tungsten carbide to differentiate it from the cast product. Chemical analyses were made on two lots of tungsten carbide tools that were supplied at different times. Table 1 shows that the tools were quite uniform. 


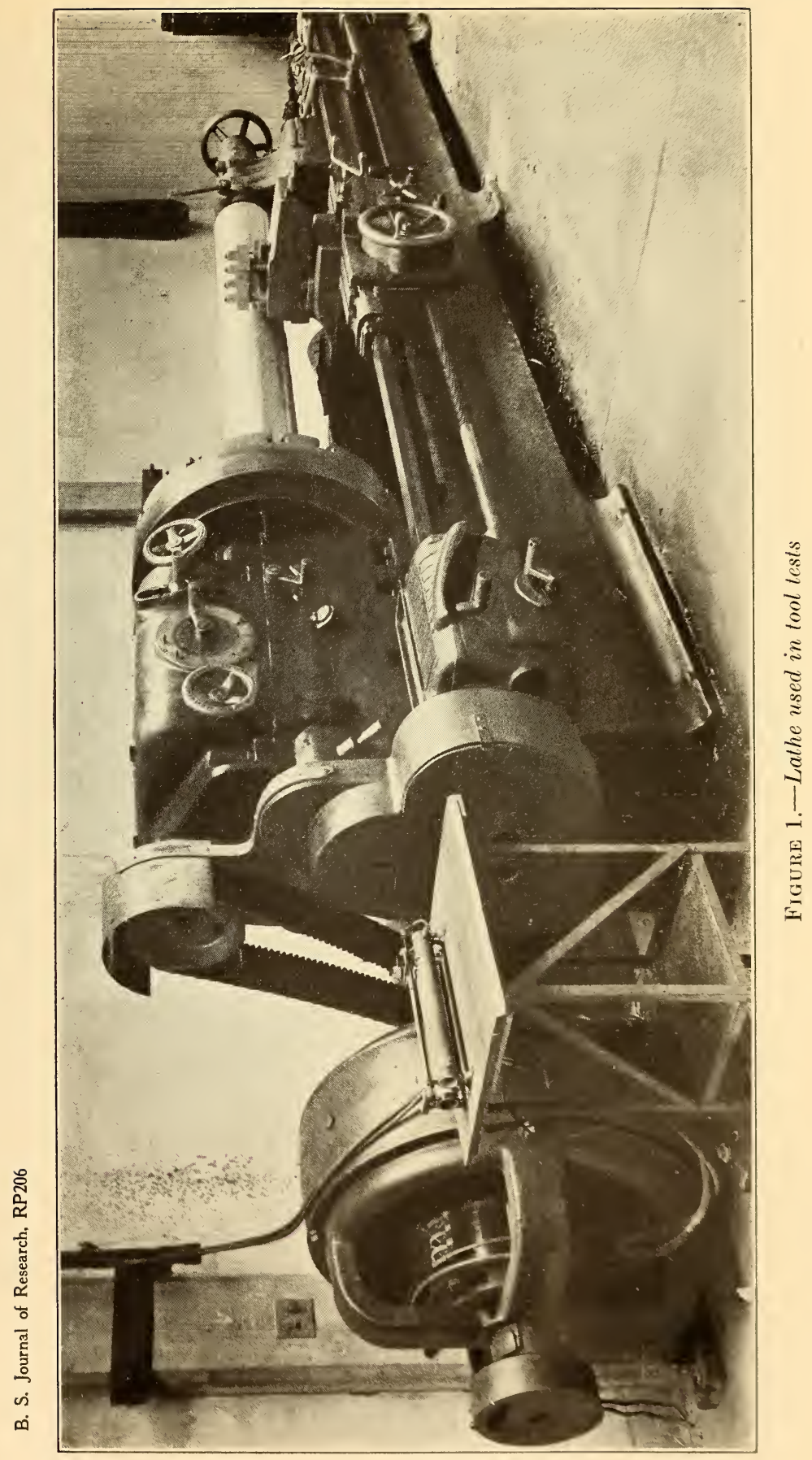




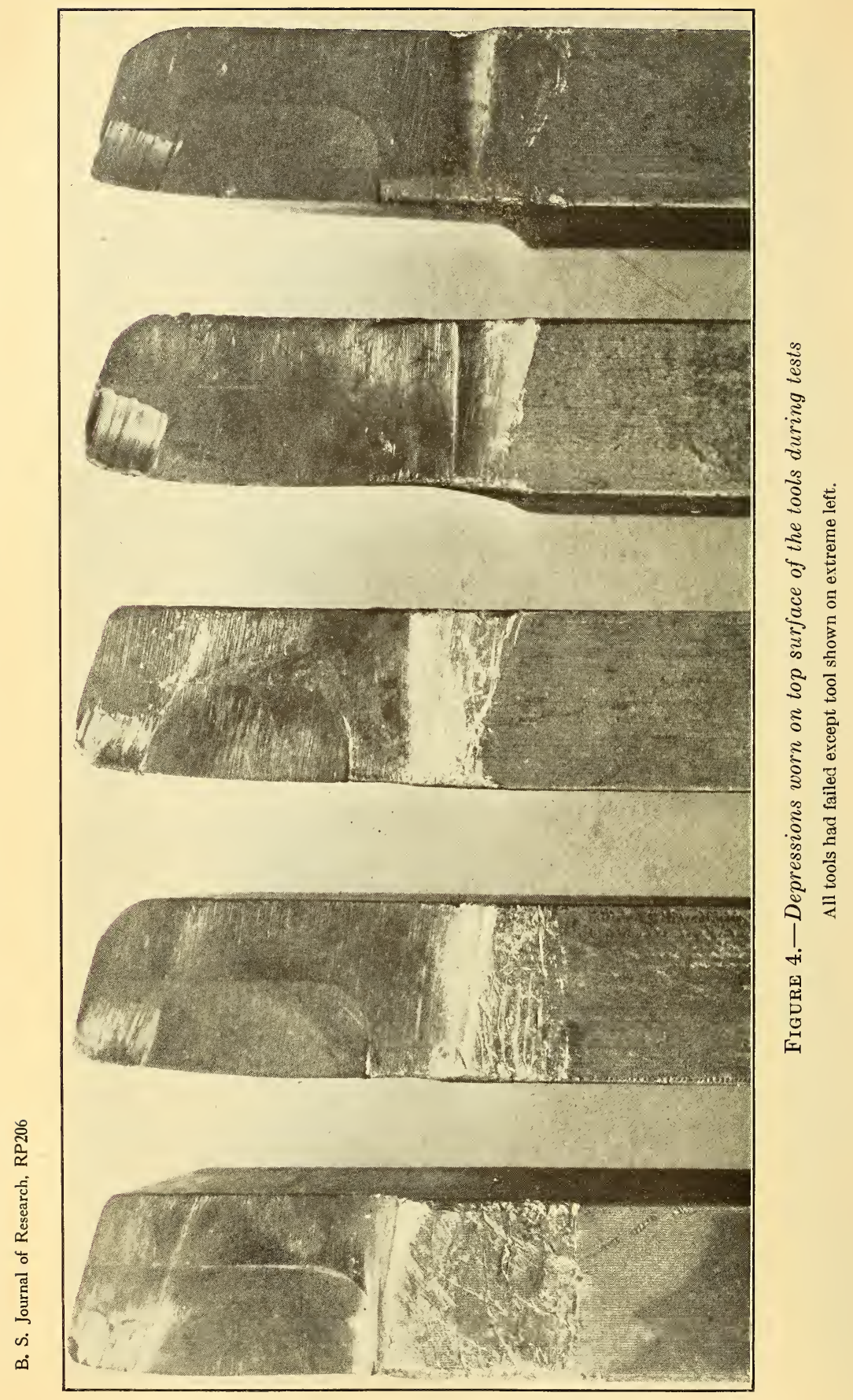




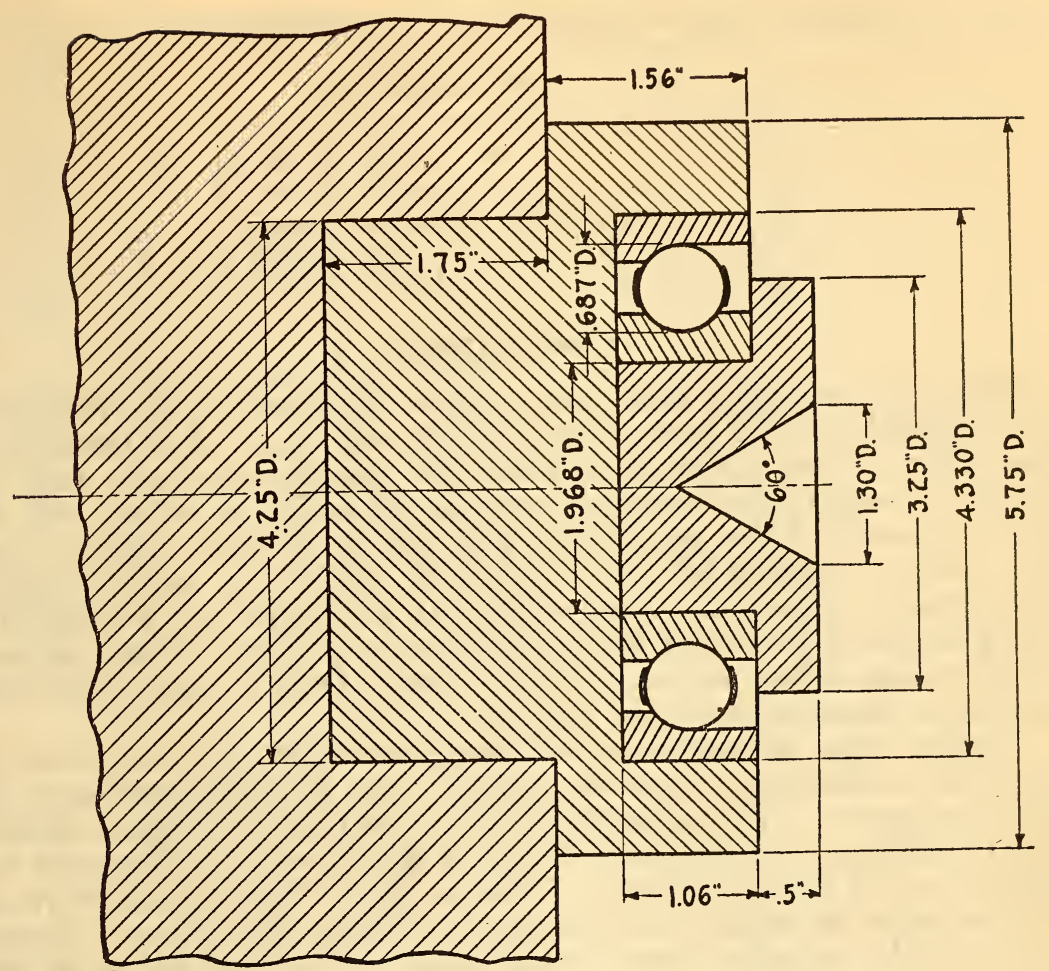

FIGURE 2.-Type of tail stock center used in lathe tests
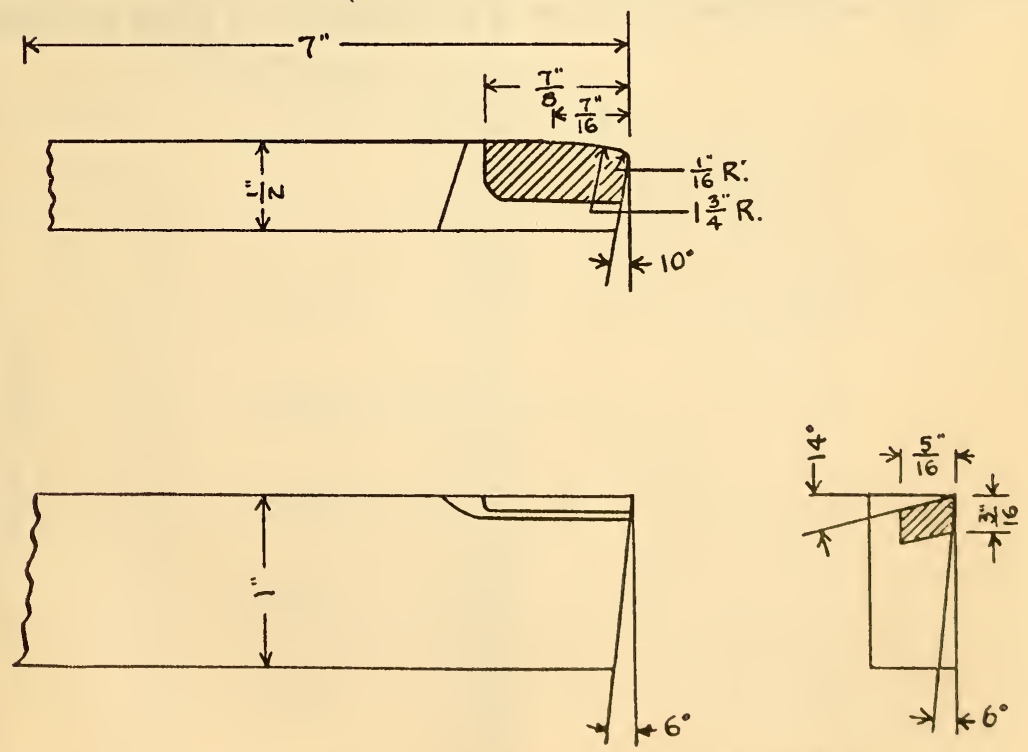

Figure 3.-Size and form of tool used in lathe tests 
TABLE 1.-Chemical analysis representative of the cemented tungsten-carbide tools

\begin{tabular}{|c|c|c|c|c|}
\hline \multirow{2}{*}{ Lot No. } & \multicolumn{4}{|c|}{ Chemical composition } \\
\cline { 2 - 5 } & $\mathrm{C}$ & $\mathrm{W}$ & $\mathrm{Co}$ & $\mathrm{Fe}$ \\
\hline & $\begin{array}{c}\text { Per cent } \\
5.3 \\
5.3\end{array}$ & $\begin{array}{c}\text { Per cent } \\
81.4\end{array}$ & $\begin{array}{c}\text { Per cent } \\
12.7\end{array}$ & $\begin{array}{c}\text { Per cent } \\
0.76 \\
.66\end{array}$ \\
\hline 2.6
\end{tabular}

\section{PROCEDURE}

From five to eight tools were tested for most of the conditions investigated, and all tests were made in sequence. For example, in the study of the effect of feed on tool performance, one tool was tested at each of the selected feeds in the series, a second tool was tested at each of the same feeds, and this procedure continued until the desired number of tools had been tested for each condition. From one to three tests were made with each tool, but no tool after being reground was used under the same conditions of test as those under which it had formerly been tested. Only average values are used for comparisons in this report.

Testing tools in sequence has long been practiced and tends to minimize variations in results arising from inhomogeneities in the metal being cut. The pieces upon which the cuts were taken, referred to as forgings, were originally from 10 to 12 inches in diameter and from 8 to 10 feet in length. In some cases the forgings were cut to diameters as small as 4.5 inches in the cutting tests. Average mechanical properties were determined on longitudinal specimens cut from the forgings so as to represent the average metal removed during cutting. The chemical composition, heat treatment, tensile properties, and Brinell hardness of the forgings are given in Table 2. 


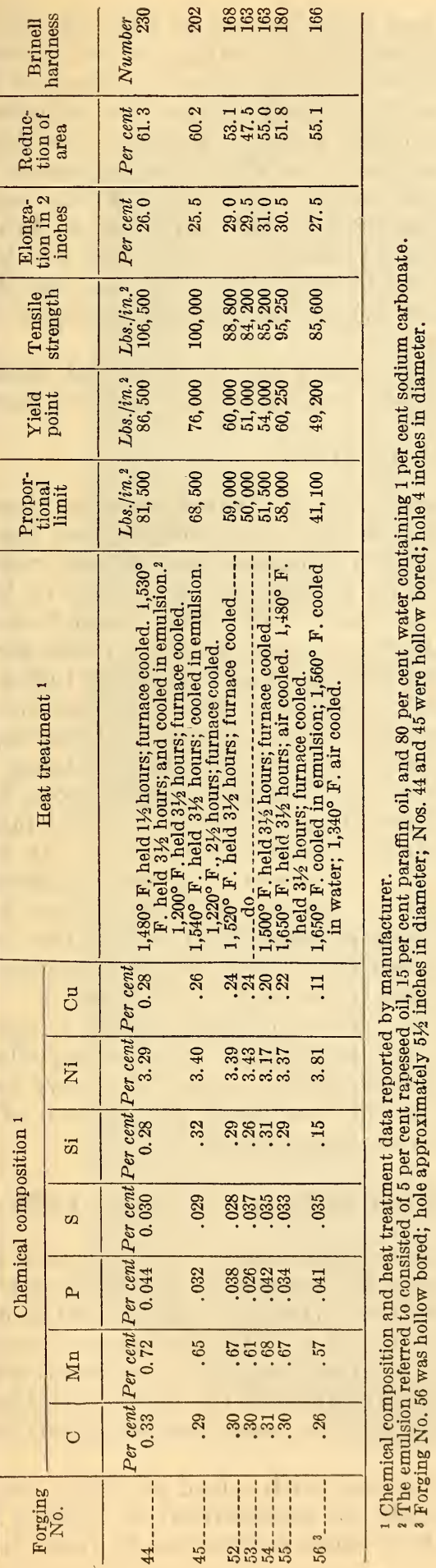


In making a cutting test the tool was clamped so that its side was at right angles to the longitudinal axis of the forging, with the end of the nose on dead center. The lathe was then set at the desired feed, the tool at the required depth, and the speed of the lathe adjusted to give the forging the desired peripheral speed. The tool was fed by hand until the desired cut was reached, after which the automatic feed was thrown in and the time recorded. The speed of the forging decreased when cutting began, but was quickly adjusted to bring it back to its original value. Before starting any test, care was taken to remove any glazed surface on the forging caused by the breakdown of the previous tool or any particles of the tool that might have become embedded in the forging.

All tests were run dry, and the cutting speed, feed, and depth of cut were varied, depending upon the purpose of each series of tests.

\section{TOOL FAILURE}

A groove was formed on the top surface of the tool near the "leading edge" soon after the tool started to cut. This depression became greater as the test progressed until a condition was finally reached when the wear was sufficient to cause a small section to chip or break out of the working portion of the tool. This "end point" usually resulted in a glazed surface on the test forging and was often accompanied by a splitting of the chip which gave an additional indication of tool failure. Thus, there was a very definite end point and one that could be recognized without much difficulty. In some of the experiments, especially those of the most severe conditions of cutting, this end point was often quickly followed by, if not simultaneous with, tool breakage which would leave doubt as to the time of tool failure. Such doubtful tests were discarded in these experiments. In some cases it would have been possible to continue to cut after the described condition was reached, but only at the expense of badly broken tools. All cutting results given in this report were obtained by the "endpoint" method described. The wear on the top and front surfaces of the tools at the time of failure is illustrated in Figures 4 and 5 .

The appearance of the forging at the time of failure of the tungstencarbide tools was very similar to the appearance of a forging when a high-speed steel tool fails under the so-called "lathe breakdown test." A glazed surface was produced on the forging at the bottom of the cut at the time of tool failure as is shown in Figure 6.

\section{EFFECTS OF CUTTING SPEED ON TOOL LIFE}

It is a well-known fact that the cutting speed of a high-speed steel lathe tool is dependent upon the quality, composition, and heat treatment of the tool and on the properties of the metal cut as well as upon the size and form of tool, feed, and depth of cut. It appeared reasonable to assume that the cutting speed of cemented tungsten-carbide lathe tools should depend upon approximately the same variables as high-speed steel tools, and it was upon this basis that the experiments were performed.

The results of tests at different speeds with a feed of 0.031 inch per revolution and depth of 0.1875 inch are summarized in Table 3 and Figure 7. Figure 7 shows that there was a continuous increase in the 


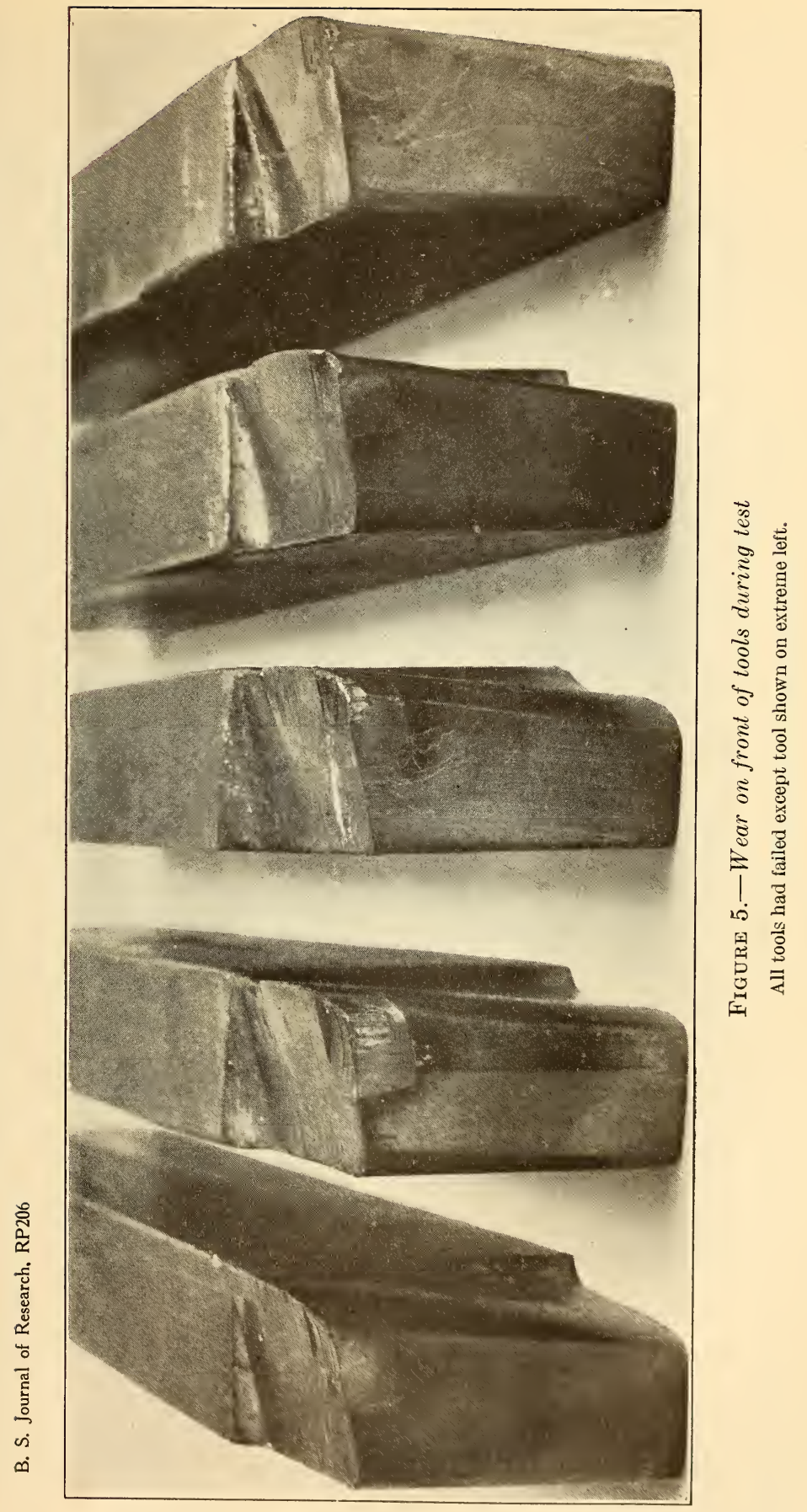


B. S. Journal of Research, RP206

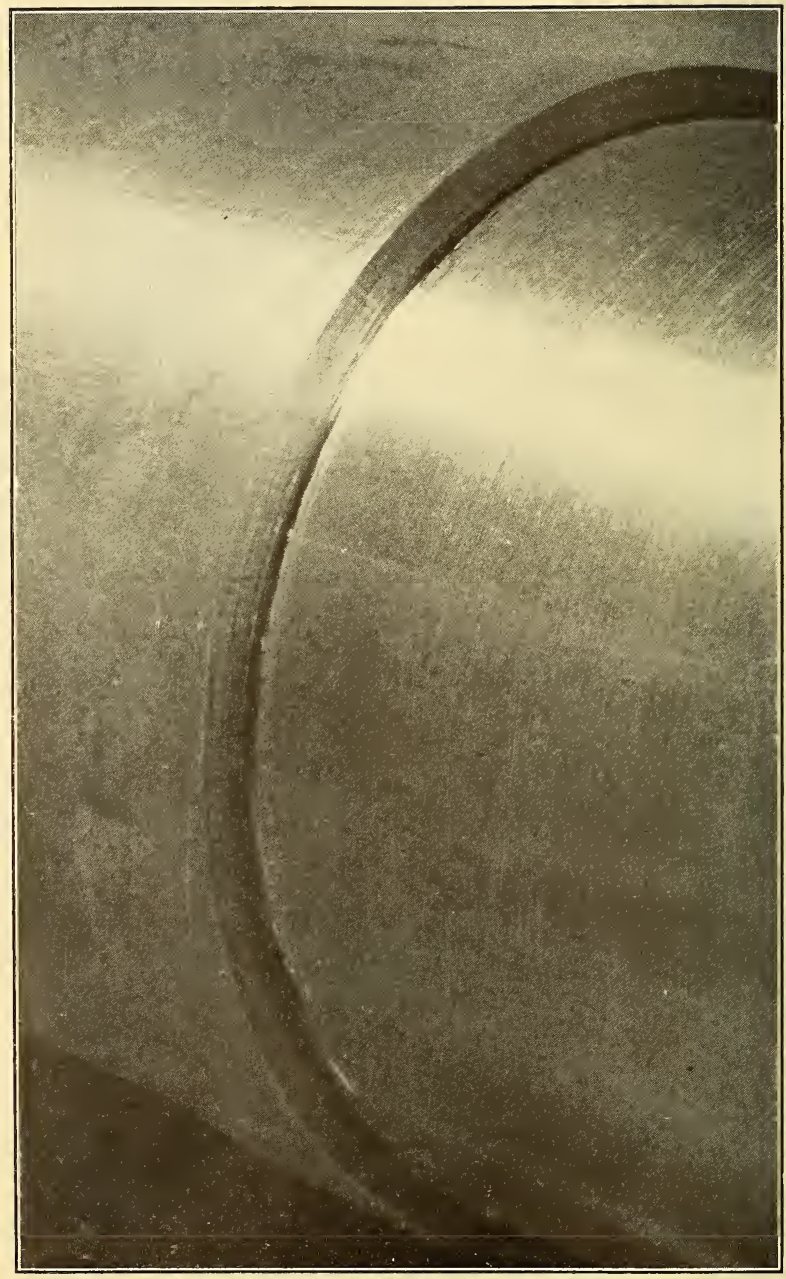

FIGURE 6.-A ppearance of test forging at time of tool failure Note the glaze at the bottom of the cut. 
life of tungsten-carbide tools as the cutting speed was decreased. Within the life range of 9 to 156 minutes the experimental results may be represented by the empirical equation

in whicn

$$
V T^{n}=c
$$

$V=$ the cutting speed in feet per minute.

$T=$ the tool life in minutes.

$c=\mathrm{a}$ constant which is dependent upon the cutting conditions other than speed. It should vary with the form and size of tools, material cut, nature of tools, feed, and depth of cut.

$n=$ constant.

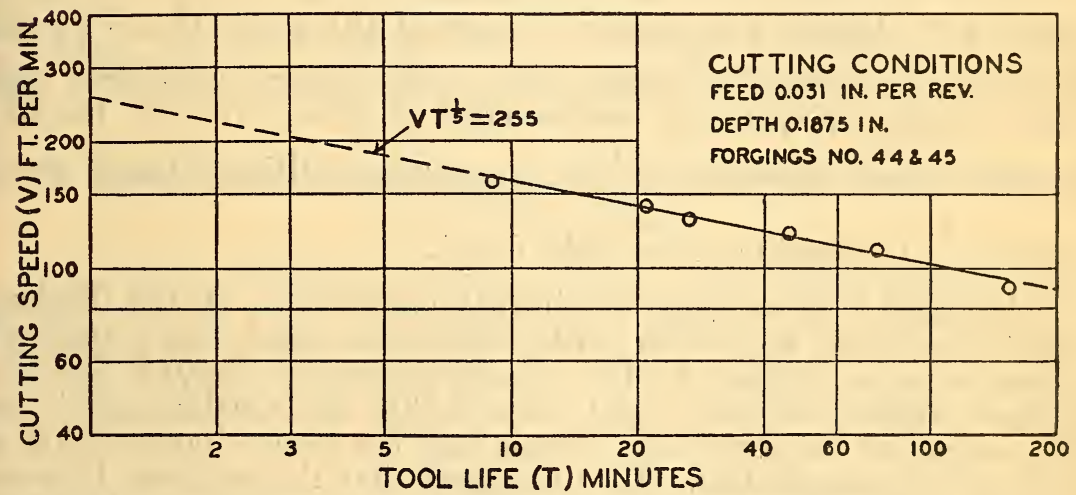

FIgURE 7.-Summary of lathe tests showing that cutting speed of cemented tungsten carbide tools varies inversely as one-fifth power of their life

Tests were made "dry" with form and size of tool shown in Figure 3. Properties of test forgings given in Table 2. Note that logarithemetic coordinates are used

TABLE 3.-Effect of speed on performance of cemented tungsten-carbide lathe tools

\begin{tabular}{|c|c|c|c|c|c|c|c|}
\hline \multicolumn{4}{|c|}{ Cutting conditions } & \multirow{2}{*}{$\begin{array}{l}\text { Number } \\
\text { of tests }\end{array}$} & \multirow[b]{2}{*}{$\begin{array}{l}\text { Average } \\
\text { tool life }\end{array}$} & \multirow{2}{*}{$\begin{array}{l}\text { Calcu- } \\
\text { lated } \\
\text { cutting } \\
\text { speed I }\end{array}$} & \multirow{2}{*}{$\begin{array}{l}\text { Average } \\
\text { power } \\
\text { required } \\
\text { in } \\
\text { cutting }\end{array}$} \\
\hline Forging No. ${ }^{2}$ & Speed & Feed & Depth & & & & \\
\hline 44 and $45 \ldots$ & $\left\{\begin{array}{r}\text { Ft./min. } \\
90 \\
110 \\
120 \\
130 \\
140 \\
160\end{array}\right.$ & $\begin{array}{c}\text { In./rev. } \\
0.031 \\
.031 \\
.031 \\
.031 \\
.031 \\
.031\end{array}$ & $\begin{array}{l}\text { Inch } \\
0.1875 \\
.1875 \\
.1875 \\
.1875 \\
.1875 \\
.1875\end{array}$ & $\begin{array}{l}5 \\
6 \\
6 \\
3 \\
6 \\
5\end{array}$ & $\begin{array}{r}\text { Min. } \\
155.9 \\
74.9 \\
45.9 \\
26.7 \\
21.2 \\
9.0\end{array}$ & $\begin{array}{c}\text { Ft./min. } \\
93 \\
108 \\
119 \\
132 \\
139 \\
164\end{array}$ & $\begin{array}{r}k w . \\
4.1 \\
5.4 \\
5.5 \\
6.2 \\
6.4 \\
6.8\end{array}$ \\
\hline
\end{tabular}

1 Computed by means of equation $V T^{n}=C$ with $n=\frac{1}{5}$ and $c=255$.

${ }^{2}$ All tests were run dry with the size and form of tool shown in Figure 3. See Table 2 for properties of forgings.

Taylor ${ }^{1}$ found the effect of cutting speed on the tool life of highspeed steels could be represented by equation (1). This empirical relationship between tool life and cutting speed with high-speed steel tools was recently confirmed by the Lathe Tool Research

1 F. W. Taylor, On the Art of Cutting Metals, Trans. A. S. M. E., 2s, p. 31; 190 i.

$118793^{\circ}-30-11$ 
Committee $^{2}$ and by tests conducted at the National Bureau of Standards ${ }^{3}{ }^{4}$ and by Ripper and Burley. ${ }^{5}$

Taylor ${ }^{6}$ reported cutting tests on carbon steels having a tensile strength of about $70,000 \mathrm{lbs}$./in. ${ }^{2}$ with tools of definite size and shape made from steel containing about 1.9 per cent carbon, 8.5 per cent tungsten, and 2 per cent chromium. He found the value $n=\frac{1}{8}$ and $c=90$, but stated:

We have made a number of experiments with different qualities of steel and find that approximately the same relation exists between the duration of cut and cutting speed for steels of different degrees of hardness. This statement, however, does not apply to cast iron.

Not all investigations have confirmed Taylor's value of the exponent " $n$." Ripper and Burley " reported the value of $n=\frac{1}{12}$ and French and Digges ${ }^{8}$ in cutting tests with modern high-speed steel tools cutting $3 \frac{1}{2}$ per cent nickel steel of about 100,000 lbs./in. ${ }^{2}$ tensile strength reported $n=\frac{1}{7}$ for roughing conditions (heavy duty) and $n=\frac{1}{10}$ for finishing cuts (light duty).

Schlesinger, ${ }^{9}$ in cutting experiments carried out at the Technological Institute at Berlin with high-speed steel and superhard metal tools in cutting a steel of approximately 100,000 lbs./in. ${ }^{2}$ (Brinell number of about 190), found that the cutting speed tool life curves for the superhard metals had the same characteristic as those of high-speed steel. His data show that the relations between tool life and cutting speed for sintered tungsten-carbide tools, where the cross section of the chip was 0.158 by 0.039 inch, could be closely represented by equation (1) when $n=\frac{1}{4.6}$. In another set of experiments which appear to have been carried out under the same test conditions it was found that $n=\frac{1}{7.1}$. With high-speed steel tools $n$ was found to be equal to about $\frac{1}{6.3}$, which is in close agreement to the value reported by the Bureau of Standards for roughing tests.

Examination of the results summarized in Figure 7 shows that the experimental values obtained for sintered tungsten carbide tools were approximately represented by equation (1) with $n=\frac{1}{5}$. Therefore, the equation

$$
V T^{\frac{1}{b}}=c
$$

\footnotetext{
2 Department of scientific and industrial research, Manchester Association of Engineers. The 1922 Report of the Lathe Tool Research Committee, published by His Majesty's Stationery Office, London.

${ }_{3}$ H. J. French and T. G. Digges, Rough Turning with Particular Reference to the Steel Cut, Trans.

A. S. M. E., 48, p. 533; 1926.

${ }^{3}$ H. J. French and T. G. Digges, Turning with Shallow Cuts at High Speeds, B. S. Jour. Research, 3, p. $829 ; 1929$.

p. W. Ripper and G. W. Burley, Cutting Power of Lathe Turning Tools, Proc. Inst. Mech. Engrs., Pts. 3 and 4, p. $1967 ; 1913$.

- See footnote 1, p. 371.

7 See footnote 5 .

8 See footnotes 3 and 4

- George Schlesinger, German Practice with Tungsten-Carbide Tools, Am. Machinist, 71, p. $37 ; 1929$.
} 
was used for all computations in this report involving the relation between the cutting speed and tool life. There was a close concordance between the experimental results and the calculated values and equation (2) should be sufficiently accurate for all practicable purposes except for extrapolating for very long tool life from tests of short duration. It is of interest to note that this law as originally developed by Taylor and his coworkers was confirmed with the cemented tungsten carbide lathe tools for duration of cut between 9 and 156 minutes under conditions widely different from those of Taylor's experiments.

Equation (2), which expresses the relation between tool life and cutting speed, is represented graphically by straight lines when logarithmetic rectangular coordinates are used. The chart reproduced in Figure 8 is of a convenient form for computing the life of tools at various speeds and makes it simpler to interpolate between the values of the constant, $c$, shown on the chart, than would be the case with the curves obtained with Cartesian coordinates.

\section{EFFECT OF FEED AND DEPTH OF CUT ON THE CUTTING SPEED}

It is not practicable to select a single cutting speed for lathe-tool testing varying widely in either feed or depth of cut because of the expense of the large amount of material that would be involved and the time required to make such test. The cutting speed has already been shown to have an empirical relation to the tool life at a given feed and depth so that in the study of the effects of feed and depth on tool performance the cutting speed was also varied. In general, cutting speeds giving an average tool life from 10 to 30 minutes were selected and then the cutting speeds for the desired tool life were computed by means of equation (2).

Two series of tests were made with the cemented tungsten-carbide tools in order to establish the relations between the cutting speed, feed, and depth of cut. One was made with a constant depth of cut of 0.1875 inch and feeds ranging from 0.031 to 0.096 inch per revolution, and the other with a constant feed of 0.031 inch per revolution and depths of cut ranging from 0.125 to 0.5625 inch.

The results of the tests made with a constant depth of cut and variable feeds are given in Table 4 , and the cutting speeds for a 90 -minute tool life with the different feeds used in the experiments are summarized in Figure 9. As shown in Figure 9, the relation between the cutting speed and the feed for a given tool life at a constant depth of cut may be represented approximately by the relation

in which

$$
V F^{m}=c_{1}
$$

$$
\begin{aligned}
& V=\text { cutting speed in feet per minute for a selected tool life. } \\
& F=\text { feed in inches per revolution. } \\
& c_{1}=\text { constant. } \\
& m=\text { constant. }
\end{aligned}
$$

When operating with cutting speeds for a selected 90 -minute tool life at a 0.1875 -inch depth of cut in cutting 3.5 per cent nickel steel forging having a tensile strength in the neighborhood of $\$ 5,000$ 


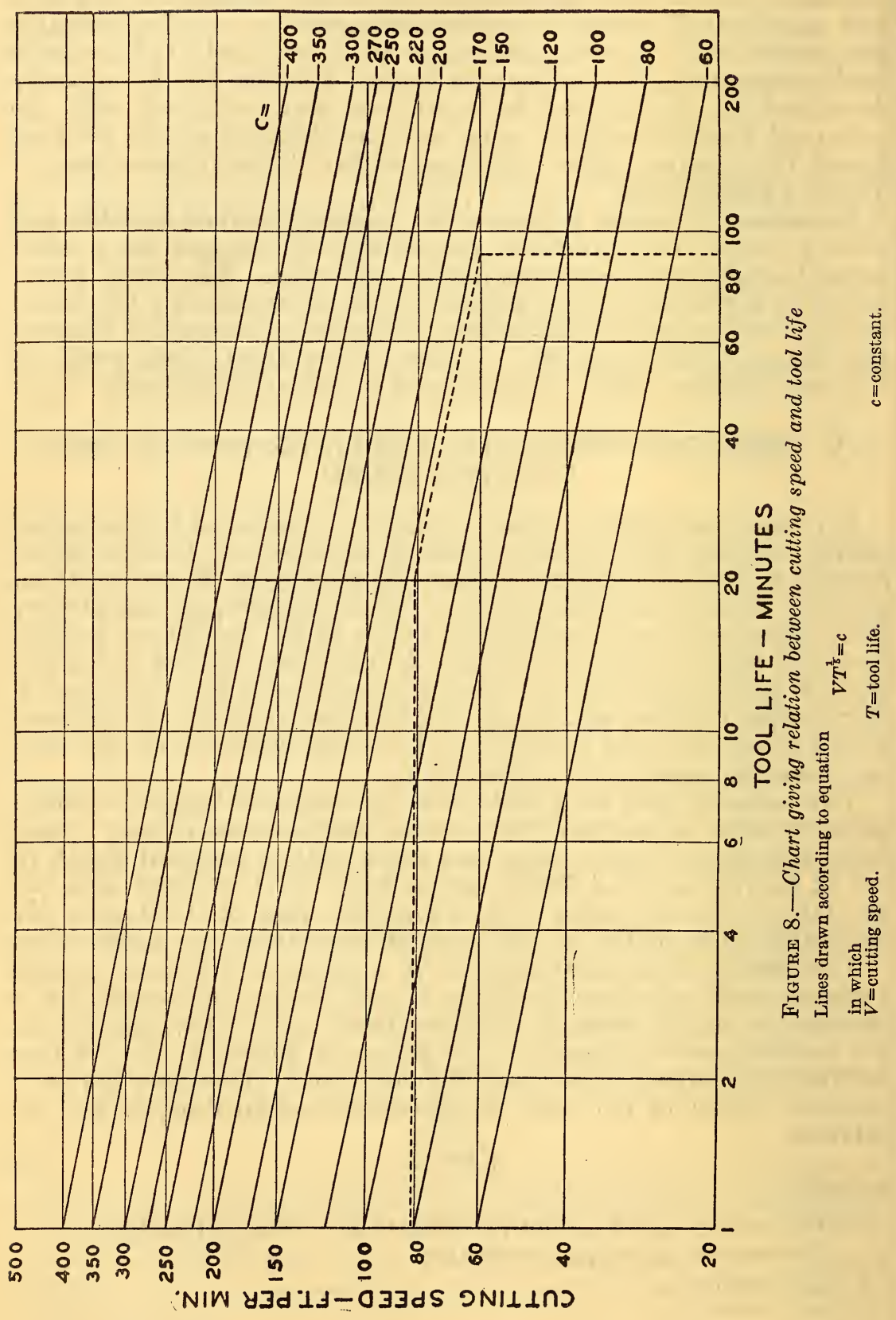


lbs./in. ${ }^{2}$, the exponent $m$ was found to be 0.58 , with $c_{1}$ equal to 16.6. Substituting these results in equation (3), we have

$$
V F^{0.58}=16.6
$$

The detailed results as recorded in Table 4 show a surprisingly close agreement between the individual tool performances. In a majority of the tests this variation was no greater than that ordinarily found when testing high-speed steel lathe tools under heavy duty.

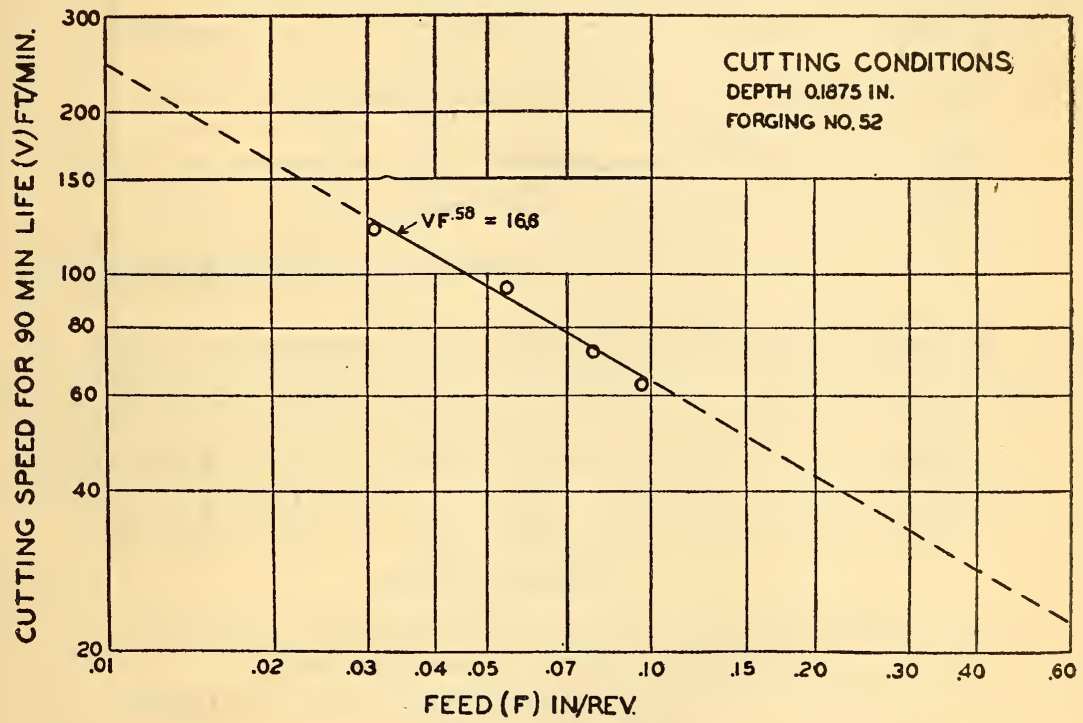

FIGURE 9.-Summary of lathe tests showing effect of feed on cutting speed for a 90-minute tool life

Tests were made "dry" with form and size of tool shown in Figure 3. Properties of forging given in Table 2

Line drawn according to equation

$V F .{ }^{88}=16.6$

in which

$V=$ cutting speed for 90-minute tool life, feet per minute.

$F=$ feed, inch per revolution.

TABLE 4.-Effect of feed on performance of cemented tungsten carbide lathe tools [All tests were run dry with the size and form of tool shown in fig. 3]

\begin{tabular}{|c|c|c|c|c|c|c|c|c|c|c|c|c|c|}
\hline \multicolumn{4}{|c|}{ Cutting conditions } & \multicolumn{8}{|c|}{ Tool life } & \multirow{2}{*}{$\begin{array}{c}\text { A rerage } \\
\text { power } \\
\text { required } \\
\text { in cut- } \\
\text { ting }\end{array}$} & \multirow{2}{*}{$\begin{array}{c}\text { Cut- } \\
\text { ting }{ }^{1} \\
\text { speed } \\
\text { for 90- } \\
\text { minute } \\
\text { tool } \\
\text { life }\end{array}$} \\
\hline $\begin{array}{c}\text { Forging } \\
\mathrm{No.}^{2}\end{array}$ & Speed & Feed & Depth & $\begin{array}{c}\text { Test } \\
1\end{array}$ & $\underset{2}{\text { Test }}$ & $\begin{array}{c}\text { Test } \\
3\end{array}$ & $\begin{array}{c}\text { Test } \\
4\end{array}$ & $\begin{array}{c}\text { Test } \\
\mathbf{5}\end{array}$ & $\begin{array}{c}\text { Test } \\
6\end{array}$ & $\begin{array}{c}\text { Test } \\
7\end{array}$ & $\begin{array}{c}\text { A ver- } \\
\text { age }\end{array}$ & & \\
\hline $\begin{array}{l}52 \\
52= \\
52 \\
52\end{array}$ & $\begin{array}{r}\text { Ft. } / \min . \\
160 \\
120 \\
105 \\
90\end{array}$ & $\begin{array}{r}\text { In./rev. } \\
0.031 \\
.054 \\
.078 \\
.096\end{array}$ & $\begin{array}{l}\text { Inch } \\
0.1875 \\
.1875 \\
.1875 \\
.1875\end{array}$ & $\begin{array}{l}\text { Min. } \\
30.6 \\
26.9 \\
23.3 \\
16.7\end{array}$ & $\begin{array}{r}\text { Min. } \\
11.5 \\
31.0 \\
8.0 \\
14.8\end{array}$ & $\begin{array}{l}\text { Min. } \\
21.2 \\
27.3 \\
12.1 \\
19.3\end{array}$ & $\begin{array}{l}\text { Min. } \\
20.8 \\
40.5 \\
16.0 \\
(3)\end{array}$ & $\begin{array}{c}\text { Min. } \\
20.8 \\
12.2 \\
(3) \\
9.1\end{array}$ & $\begin{array}{l}\text { Min. } \\
27.3 \\
26.4 \\
12.7 \\
16.7\end{array}$ & $\begin{array}{l}\text { Min. } \\
25.0 \\
(3) \\
12.6 \\
(3)\end{array}$ & $\begin{array}{l}\text { Min. } \\
22.5 \\
27.4 \\
14.1 \\
15.3\end{array}$ & $\begin{array}{r}k w . \\
5.5 \\
7.1 \\
5.5 \\
9.3\end{array}$ & $\begin{array}{r}\text { Ft./min. } \\
121 \\
04 \\
\\
73 \\
03\end{array}$ \\
\hline
\end{tabular}

1 Computed from average tool life by means of equation $V T^{\frac{1}{3}}=c$.

2 See Table 2 for properties of forging.

Tool broke. 
The results of the cutting tests made with a constant feed and variable depths are given in Table 5. The cutting speeds for a 90-minute tool life with the different depths used in the experiments are summarized in Figure 10. The results show that there was a

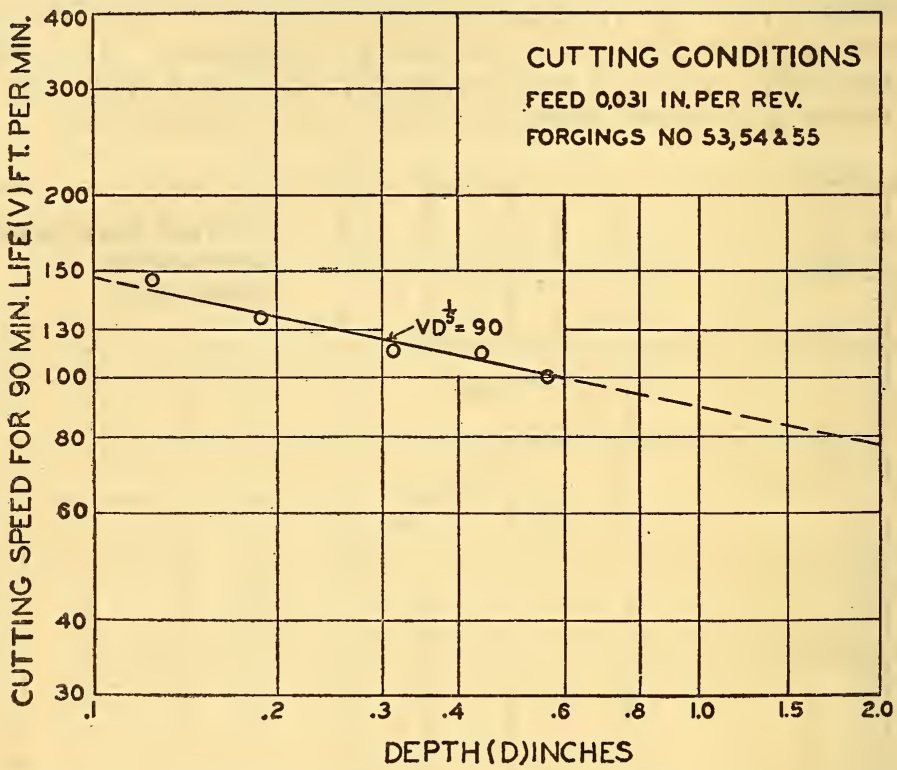

FIGURE 10.-Summary of lathe tests showing effect of depth of cut on cutting speed for a 90-minute tool life

Tests were made "dry" with form and size of tool shown in Figure 3. Properties of forgings given in Table 2

Line drawn according to equation

in which

$$
V D^{\frac{1}{6}}=90
$$

$V=$ cutting speed for 90 -minute life, feet per minute.

$D=$ depth of cut, inches.

continuous increase in the cutting speed with decrease in depth of cut and that the relation between the cutting speed and depth of cut with a constant feed and given tool life may be represented by the equation

in which

$$
V D^{p}=c_{2}
$$

$V=$ cutting speed in feet per minute for a selected tool life.

$D=$ depth of cut in inches.

$c_{2}=$ constant.

$p=$ constant.

$p$ was found to be equal to 0.2 and $c_{2}$ was equal to 90 , for a 90 -minute tool life, and with a feed of 0.031 inch per revolution and depths of cut varying from 0.125 to 0.5625 inch. Substituting these results in equation (5) we have

$$
V D^{0.2}=90
$$

An examination of Figure 10 shows that there was a close agreement between the experimental and calculated values over a wide range of depths of cut. 
As already stated, the cutting speed for a given tool life is dependent upon the quality and composition of the tool, the properties of the metal cut, size and form of tool, feed, and depth of cut.

TABLE 5.-Effect of depth of cut on performance of cemented tungsten carbide lathe tools

[All tests were run dry with the size and form of tool shown in fig. 3]

\begin{tabular}{|c|c|c|c|c|c|c|c|}
\hline \multicolumn{4}{|c|}{ Cutting conditions } & \multirow{2}{*}{$\begin{array}{l}\text { Number } \\
\text { of tests }\end{array}$} & \multirow{2}{*}{$\begin{array}{l}\text { Average } \\
\text { tool life }\end{array}$} & \multirow{2}{*}{$\begin{array}{c}\text { Average } \\
\text { power } \\
\text { required } \\
\text { in cutting }\end{array}$} & \multirow{2}{*}{$\begin{array}{l}\text { Cutting } \\
\text { speed 1 } \\
\text { for } 90- \\
\text { minute } \\
\text { tool life }\end{array}$} \\
\hline Forging No.2 & Speed & Feed & Depth & & & & \\
\hline 53,54 , and 55 & $\left\{\begin{array}{r}F t . / \min . \\
200 \\
180 \\
160 \\
150 \\
140\end{array}\right.$ & $\begin{array}{r}\text { In./rev. } \\
0.031 \\
.031 \\
.031 \\
.031 \\
.031\end{array}$ & $\begin{array}{r}\text { Inch } \\
1 / 8 \\
3 / 16 \\
5 / 16 \\
7 / 16 \\
9 / 16\end{array}$ & $\begin{array}{l}8 \\
8 \\
8 \\
7 \\
7\end{array}$ & $\begin{array}{r}\text { Minutes } \\
17.7 \\
15.1 \\
14.4 \\
18.5 \\
16.5\end{array}$ & $\begin{array}{r}k w . \\
5.7 \\
7.2 \\
11.8 \\
16.6 \\
20.6\end{array}$ & $\begin{array}{r}\text { Ft./min. } \\
144 \\
126 \\
111 \\
109 \\
100\end{array}$ \\
\hline
\end{tabular}

1 Computed from the average tool life by means of equation $V T 1 / 5=c$.

2 See Table 2 for properties of forgings.

In these experiments the quality and composition of the tools, size and form of tools, and the metal cut were kept as near constant as possible, so that the cutting speed for a given tool life was dependent only upon the feed and depth of cut.

From equations (4) and (6) for a 90-minute tool life we have

$$
V F^{0.58} D^{0.2}=K=12
$$

or

$$
V=\frac{K}{F^{0.58} D^{0.2}}=\frac{12}{F^{0.58} D^{0.2}}
$$

The equations given in this report check experimental values closely, and can be used as the basis for computing speeds for a selected tool life under varying conditions, provided the size, form, quality, and composition of tools and the type of cutting material herein described are used. If the tool life is known at some one speed, feed, and depth of cut, these computations require only the use of equations (2) and (7). The computations necessary in applying equations (2) and (7) are, however, tedious because of the form of equation (7), and to avoid these computations the chart reproduced in Figure 11 was constructed. This chart is adopted for the reading of the various cutting speeds permitting a 90 -minute tool life with various combinations of feeds and depth of cut. With the logarithmetic rectangular coordinates used for depth of cut and feed, the cutting speed $(\bar{V})$ (shown on chart, fig. 11) for 90 -minute tool life is represented by straight lines.

In using this chart, find the intersection of the desired feed and depth coordinates. This point of intersection will usually fall between the sloping lines representing the cutting speed. This value will give the approximate cutting speed ( $V$ ) for a tool life of 90 minutes. The cutting speed for a tool life within the range of 1 to 200 minutes may be obtained from the charts reproduced in Figures 11 and 8 or by equations (7) and (2), 
For example, if it is required to compute the cutting speed for a 90 -minute tool life with a feed of 0.08 inch per revolution and 0.5 inch depth of cut, from Figure 11 it will be seen that the 0.08 inch per revolution feed and 0.5 -inch depth coordinates intersect at the speed line corresponding to 60 feet per minute. Now, if the cutting speed for 20-minute tool life with the same feed and depth of cut is desired, we have the value of 81 as given by the chart shown in Figure 8 . This latter value is obtained by finding the intersection of the abscissa representing a tool life of 90 minutes (follow the dotted line in fig. 8) with the ordinate representing a cutting speed of 60 feet per minute, then by interpolating by following the straight line (shown in fig. 8 as $c=150$ ) until this line intersects the abscissa representing a tool life of 20 minutes.

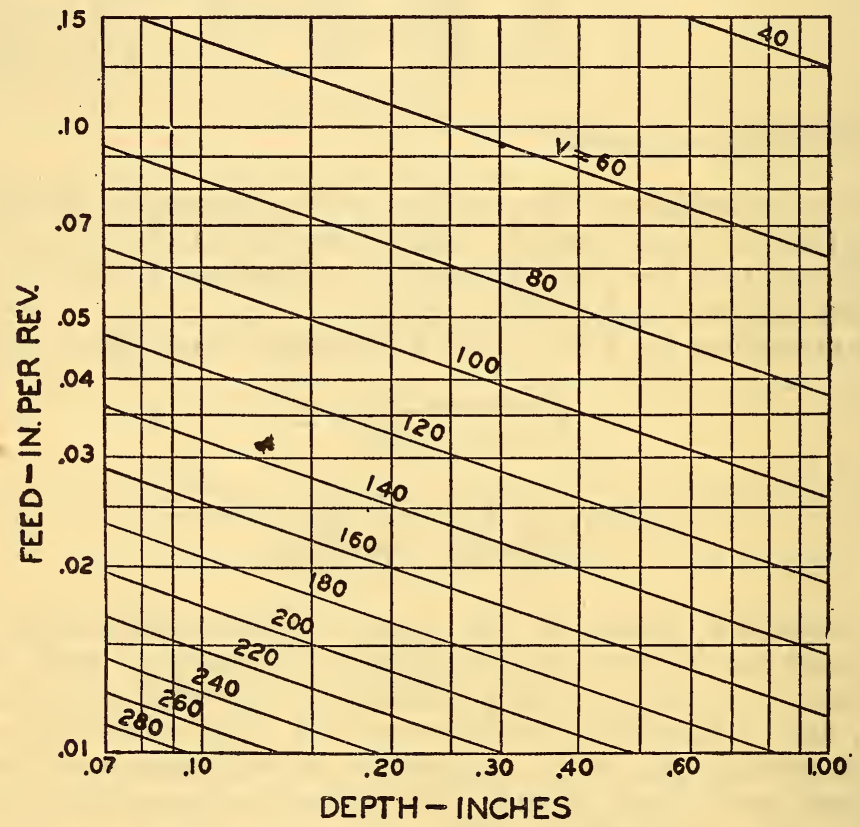

FIGURE 11.-Cutting speed-feed-depth chart for selected size, and form of tools and cutting material used in experiments

This gives cutting speed for 90-minute tool life in dry turning 3.5 per cent nickel steel of approximately $85,000 \mathrm{lbs}$. in. ${ }^{2}$ tensile strength at various feeds and depths. The maximum feed and depth values as shown on chart are greater than those that can be used with $1 / 2 \times 1$ inch cemented tungsten carbide tools. Refer to text for discussion of use of chart

Figure 11 was constructed with the lines representing the permissible cutting speeds for 90 -minute tool life, ranging from 40 to 280 feet per minute at intervals of 20 feet per minute. Cutting speeds other than those shown on the chart for a 90-minute tool life may be estimated with a reasonable degree of accuracy by extrapolation.

The limits of the values for feed and depth as given in Figure 11 are in excess of those that can be used with 0.5 by 1 inch cemented tungsten-carbide tools. However, it is possible to use a wide range of feeds and depths of cut with this size tool. This chart should 
also be applicable (with modifications) to larger tools than those used in the experiments.

As already stated, equation (7) does not take into consideration changes in size and form of tools and variations in materials cut. The need of such tests becomes immediately apparent in order to extend the relations between the relatively short time laboratory test of this new cutting material to its wide field of industrial work.

As shown by equation (7), the cutting speed is not affected equally by changes in feed and depth of cut. A higher cutting speed is associated with a deep cut and fine feed than with a corresponding combination of coarse feed and shallow cut. Equations (2) and (6) show that the exponents, $n$ and $p$, expressing the relation between cutting speed and tool life and the cutting speed and depth of cut are equal.

\section{GENERAL COMMENTS ON THE LATHE TESTS}

Despite the fact that cemented tungsten carbide contains appreciable proportions of cobalt, it is a relatively brittle material and for this reason the cutting tools must be well supported. For these tests the carbide tips were joined to the tool shank by copper brazing in a hydrogen atmosphere. Hoyt ${ }^{10}$ stated:

It has been found that tungsten-carbide tips which are rigidly welded to the shank are only too apt to come off, either directly after the tool is made, or after being put in service. This is due to thermal stresses which are set up by temperature changes and differences in the coefficients of expansion of the carbide and the steel. This circumstance accounts for the popularity of copper brazing, because here the thin layer of copper affords a soft cushion which absorbs such stresses without transmitting them to the carbide tip. On the other hand, copper softens at elevated temperatures, so that it is necessary, in the design of the tool, to remove the joint far enough away from the cutting edge so that it does not get dangerously hot during operation.

This method of attaching the carbide tip was satisfactory for most of the conditions used in the cutting tests, although premature failure in several tests resulted because of the rupture of this bond.

The heaviest cuts used with the 0.5 by 1 inch tools were probably greater than those that could be used in ordinary shop practice where cost, due to tool breakage, becomes important. The carbide tips of the tools were reduced in size by grinding and weakened accordingly so that most of the tool breakage was confined to the heaviest cuts with tools that had been reground. The test showed that the tools could be used under relatively heavy duty provided they were properly supported and not subjected to vibration.

The forces on a lathe tool, while cutting, are practically independent of the cutting speed and are dependent upon the cross section of the chip. It is evident from this principle that tungstencarbide tools should be used at relatively high speeds and for light cuts in order to keep tool breakage at a minimum. As shown by equation (2), the cutting speed varies as the one-fifth power of the tool life. This indicates that a small change in cutting speed causes a correspondingly large change in the tool life so that the higher cutting speeds are obtained only at the expense of shorter tool life. The most economical cutting conditions must therefore be a com- 
promise between several factors such as increase in cutting speed with decrease in tool life and tool breakage in order to remove the maximum amount of metal in the minimum time at the least cost.

Some idea of the relation between the cutting speeds associated with tungsten-carbide tools and high-speed steel tools may be obtained from the cutting speed-tool life curves reproduced in Figure 12. Attention is directed to the fact that the two curves were not made under identical conditions of cutting, and only a general comparison can be made from these results. For example, the tungstencarbide tools were larger than those used in the high-speed steel experiments and the tool angles were different for the two types of tools.

The high-speed steel tools were of the 18 per cent tungsten type, quenched in oil from $2,400^{\circ} \mathrm{F}$. and tempered at $1,100^{\circ} \mathrm{F}$. These tools were 0.25 by 0.5 inch in size, and were ground to a front and

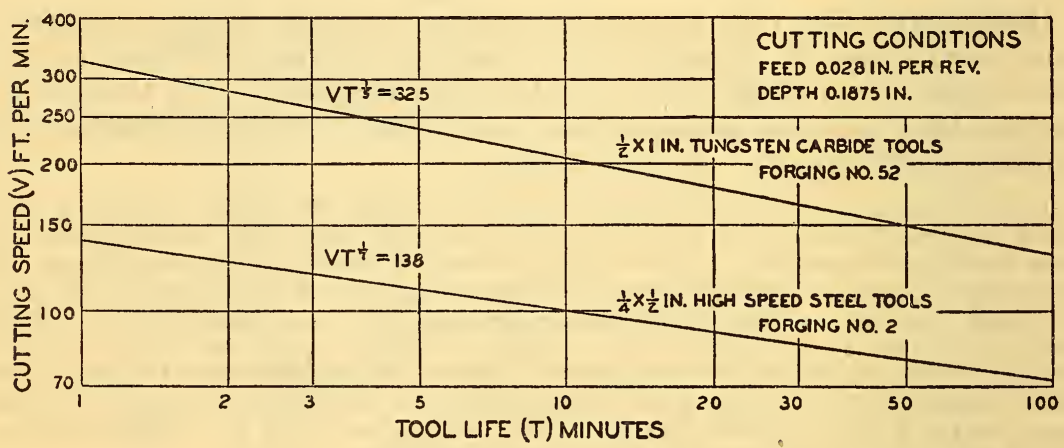

FIGURe 12.-Summary of relation between cutting speed and tool life with tungsten carbide and high speed steel lathe tools

Tests were run "dry" with the size and form of tools shown in report. Properties of forgings given in Table 2

For cemented tungsten carbide tools, line drawn according to equation

$$
V T^{\frac{1}{5}}=325
$$

For high-speed steel tools line drawn according to equation

in which

$$
V T^{\frac{1}{7}}=138
$$

$V=$ cutting speed, feet per minute.

$T=$ tool life, minutes.

side clearance of $6^{\circ}$, side slope of $8^{\circ}$, back slope of $14^{\circ}$, and a nose radius of 0.125 inch. The cutting materials (as shown in Table 2) had approximately the same chemical and physical properties, but as already pointed out, it does not necessarily follow that the two forgings have the same cutting properties. Both forgings were of the 3.5 per cent nickel type, heat treated to give a tensile strength of about $85,000 \mathrm{lbs}$./in. ${ }^{2}$

Figure 12 shows that considerably higher cutting speeds (under certain conditions) were obtained with the tungsten-carbide tools than with the high-speed steel tools. Also, the slope of the straight lines representing the relations between cutting speed and tool life with the logarithmetic system of coordinates were different for the two types of tools. The slope of the curves obtained with the tungsten-carbide tools was greater than that obtained with the high- 
speed steel tools. This means that the two curves tend to approach each other, and the differences between the cutting speeds of the two materials decrease with increase in tool life. If these curves are extrapolated to an extremely long tool life, then the curves will cross and the high-speed steel tools would show higher cutting speeds than the tungsten-carbide tools. However, such long time cutting can not be extrapolated with any degree of accuracy from the present empirical equations, and it is also doubtful if cutting conditions resulting in such long tool life would ever be practicable in modern shops from an economical standpoint.

Cemented tungsten-carbide tools have the property of red hardness to a remarkable degree. This property permits higher cutting speeds under certain conditions than is the case with the best tool steels.

While the tungsten-carbide tools were considerably superior to those of high-speed steel in cutting 3.5 per cent nickel-steel forgings of about $85,000 \mathrm{lbs}$./in. ${ }^{2}$ tensile strength, it does not follow that the same degree of superiority will be obtained under widely different cutting conditions, especially where heavy feeds and deep cuts are used. Therefore, it is necessary to know exactly the cutting conditions in order to make a comparison of the two types of tools.

No direct indication of the performance of the tungsten-carbide tools could be detected by the types of chips produced in the lathe tests. In general, the chips came off in very long ribbons during the first part of the cut and then became shorter with more curl as the cutting time increased. A short time before tool failure the chips were approximately 0.5 to 1 inch in length. While these chips were characteristic for some of the conditions employed, especially with tools tested on forgings No. 52, they were not characteristic of the tools tested under conditions of varying depths of cut on forgings Nos. 54 and 55. In the latter case the long chips often continued until tool failure.

The power required in cutting was determined in all of the lathe tests with tungsten-carbide tools and was determined at frequent intervals throughout the life of the lathe tools, so that only average values were obtained. The instruments used, however, did not permit determinations of the fluctuations or the maximum momentary power consumption. The results given in Table 3 show that at constant feed and depth of cut the power was approximately proportional to the cutting speed. The exact relations between the feed and depth of cut and the power consumed can not be established at this time. The results given in Tables 4 and 5 show that there was an increase in the power with increase in feed or depth. However, as already pointed out, the feed and depth experiments were not made at a constant speed, so that the magnitude of the changes in power due to changes in feed or depth can not be established from the limited number of tests made. The power determinations are included with the test results in order to show that it is necessary to have machines equipped with powerful driving units in order to utilize the full capacity of tungsten-carbide tools. 


\section{SUMMARY AND CONCLUSIONS}

1. The primary object of this investigation was to develop a method of testing tungsten-carbide lathe tools under heavy duty and to extend to the new cutting material some of the empirical laws originally developed by Taylor and his associates for tough turning with carbon and high-speed steel tools.

2. The so-called lathe breakdown test for high-speed steels was found applicable for testing cemented tungsten-carbide tools under heavy duty.

3. The characteristics of the cutting speed-tool life curves for tungsten carbide tools-were similar to those of high-speed steel tools.

4. In dry rough turning 3.5 per cent nickel steel of about 105,000 lbs./in. ${ }^{2}$ tensile strength, with a constant feed, death of cut, tool size, and form, the relation between cutting speed and tool life within the life range of 9 to 156 minutes may be represented by the empirical equation

where

$$
V T^{n}=c
$$

$V=$ the cutting speed in feet per minute.

$T=$ the tool life in minutes.

$n=$ constant $=\frac{1}{5}$

$c=$ constant which is dependent upon the conditions of cutting.

It will vary with the form and size of tools, materials cut, feed and depth of cut.

5. For a given area of cut, higher cutting speeds are obtained with deep cuts and fine feeds (within limits) than with shallow cuts and coarse feeds.

6. The relation between cutting speed, feed, and depth of cut in terms of the experimental conditions may be represented by the empirical equation

in which

$$
V F^{0.58} D^{0.2}=K=12
$$

$V=$ the cutting speed for a selected tool life.

$F=$ feed in inches per revolution.

$D=$ depth of cut in inches.

$K=$ constant $=12$ for the experimental conditions.

7. Higher cutting speeds are obtained with cemented tungstencarbide tools under certain conditions of cutting than with highspeed steel tools.

8. Cemented tungsten-carbide tools are brittle, but when properly supported will produce excellent results under certain cutting conditions.

9. High cutting speeds with relatively fine cuts are more favorable to the successful application of tungsten-carbide tools than heavy cuts at slower speeds.

10. Machines capable of operating at high speeds with powerful driving units are necessary to utilize the full cutting capacity of cemented tungsten-carbide tools. 


\section{ACKNOWLEDGMENTS}

The writer acknowledges the assistance and suggestions of Dr. S. L. Hoyt and W. E. Smith. The Carboloy Co. (Inc.) donated all tungsten-carbide test tools and the majority of test forgings.

Grateful acknowledgment is also due to Dr. R. L. Dowdell, senior metallurgist, for his aid and constructive suggestions in the presentation of the test data, to W. V. Magruder, jr., laboratory aid, and C. F. Raab, machinist, formerly of the Bureau of Standards, for their assistance in assembling the equipment and for carrying out many of the tests.

Washington, March 8, 1930. 
